\title{
The Effect Of Buyer Governance Structures On Performance: Contextual Effects Of Interfirm Benevolence
}

Minhye Park, Sungkyunkwan University, South Korea

Hanah Choi, Sungkyunkwan University, South Korea

Donghu Hahn, Yeung Jin College, South Korea

\begin{abstract}
Researchers identify two types of organizational governance: unilateral governance and bilateral governance. Although interfirm governance is at the core of interfirm relationships, little research exists on mechanisms that strengthen the weak spots in the dynamics of interfirm governance and multiple governance structures. This study introduces the concept of interfirm benevolence, and attempts to enhance our understanding of the conditions under which buyers rely on interfirm governance. The results indicate that the interfirm governance practices of a buyer tend to produce higher levels of supplier performance when a supplier trusts in the benevolence of the buyer. Also, this study shows that when a benevolent buyer uses both unilateral and bilateral governance simultaneously, suppliers perform positively.
\end{abstract}

Keywords: Formal Control; Informal Control; Benevolence

\section{INTRODUCTION}

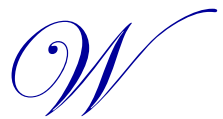

hen it comes to inter-organizational relationships, researchers have identified several types of interfirm governance, including monitoring (Celly \& Frazier, 1996; Lal, 1990), vertical control (Bello \& Gilliland, 1997; Heide \& John, 1988), relational norms (Heide \& John 1992), contracts (Cannon, Achrol, and Gundlach, 2000), and pre-qualification (Stump \& Heide, 1996). These mechanisms of governance have been found to effectively impact the behavior and performance of exchange partners (Coleman, 1990).

Interfirm governance, however, is known to have some key weak spots, (Young, Sapienza and Baumer, 2003; Ghoshal \& Moran, 1996) including the existence of a sense of autonomy among cooperating parties (Ghoshal \& Moran, 1996), and a lack of understanding among parties involved in exchange transactions (Young, Sapienza and Baumer, 2003). Despite the advanced understanding of interfirm governance that previous research has provided, there are several gaps in the literature that must be addressed.

First, even though interfirm governance is at the core of interfirm relationships, little existing research explores mechanisms to reduce the weaknesses of interfirm governance. Because interfirm governance plays an important role in inter-organizational relationships (e.g., Heide, 1994), the development of mechanisms to protect parties involved in exchange transactions is a key task for the effective management of interfirm relationships. Thus, the identification of mechanisms by which exchange parties are able to reduce weaknesses in the dynamics of their partnership is needed.

Second, even though some research has been conducted on the simultaneous use of multiple governance structures, including on the effects of multiple governance on interfirm performance (Jap \& Ganesan, 2000), complementation relationships between governances (Cannon, Achrol, and Gundlach, 2000), and interdependence relationships between governances (Stump \& Heide, 1996), little is known regarding the best circumstances under which the simultaneous use of multiple governance structures produces positive interfirm performance. 
Third, previous research on multiple governance does not investigate conditions under which multiple governance produces high levels of performance, with the exception of the work of Cannon, Achrol, and Gundlach (2000). When exchange transactions are affected by uncertainty and relationship-specific adaptation, companies that rely on multiple governance increase interfirm performance levels (Cannon, Achrol, and Gundlach, 2000). However, no research exists on the best conditions under which exchange parties are able to improve performance by relying on multiple governance.

This study introduces the concept of interfirm benevolence, a dimension of trust, to contribute to the existing literature. Benevolence, defined as the unilateral belief of an exchange party in the concern of its partners for the party's well-being (Kwaku \& Li, 2002), has emerged as a central tenet in the existing literature about interorganization relationships (Wilson, 1995). Interfirm benevolence allows exchange parties to accept and yield to the control of partners for the sake of producing long-term benefits via the partner relationships.

The purpose of this study is to enhance our understanding of the conditions under which buyers rely on interfirm governance. The study accomplishes this in two ways. First, the study investigates two type of governance that may improve interfirm performance, including unilateral and bilateral governance. We propose that any buyer relying on interfirm governance tends to produce high performance levels when suppliers trust in the benevolence of the buyer. Second, this study examines optimal conditions for multiple governance. We argue that a buyer can effectively use both unilateral and bilateral governance when suppliers trust the benevolence of the buyer.

The next section discusses the theoretical background of trust and governance in the context of exchange relationships. Research hypotheses are developed thereafter.

\section{THEORETICAL BACKGROUND AND HYPOTHESES}

\section{Interfirm Benevolence}

Benevolence refers to the unilateral belief of a supplier in the concern of the buyer for the well-being of the supplier (Kwaku \& Li, 2002). The abstractions of interfirm trust present ample opportunities for the betrayal of a dyadic partner (Lim, Smith, and Kim, 2014; Granovetter, 1982). Indeed, the greater the trusting partner's level of benevolence is, the greater potential gain there is to be had from cheating on the benevolent partner (Jun, Kabadayi and Ryu, 2014). Accordingly, a party's trust in the benevolence of its partner causes the party to be far more vulnerable than a party that lacks trust in a partner's benevolence.

A supplier needs to calculate how much it can trust a buyer, because a supplier's trust in the benevolence of a buyer exposes the vulnerability of the supplier to the buyer (Hur et al., 2014; Madhavan \& Grover, 1998). A supplier estimates a buyer's benevolence, resulting in the supplier's belief in this benevolence (Doney \& Cannon, 1997). Thus the supplier's trust in a buyer's benevolence is positively associated with the supplier's expectations that the buyer has benevolent intentions (Moorman et al., 1992). A supplier's trust in buyer benevolence is also related to an estimation of low probability that the buyer will display deceptive behavior.

\section{Types of Interfirm Governance}

Researchers identify two types of organizational governance: unilateral governance and bilateral governance (Weitz \& Jap, 1995; Heide, 1994; Ouchi, 1979). The distinction between unilateral and bilateral control is based on whether both buyers and suppliers participate in making decisions (Weitz \& Jap, 1995). Unilateral governance relies on the unilateral decision making of just one party, while bilateral governance is based on mutual participation in decisionmaking by both parties in an exchange relationship.

Bradach and Eccles (1989) defined control as an exchange facilitator, asserting that trust facilitates exchange-based relationships. Accordingly, the authors treat trust as a control mechanism. However, the mechanism of control is intended to change an exchange partner's behavior. Trust itself is a unilateral belief in the benevolence of a partner, and consequently, this unilateral belief will not control behaviors among exchange partners (Das \& Teng, 1998). Accordingly, this study does not treat trust as a mechanism of control. 
This study adopts two types of governance, including monitoring and the norm of flexibility. Because monitoring involves unilateral behavior, such as the observation of an exchange partner, monitoring represents a unilateral control mechanism. In contrast, the norm of flexibility is an implicit rule for the mutual benefit of both parties. Thus the norm of flexibility represents bilateral governance.

Unilateral governance is based on the efforts of a more powerful party to impact the behavior of its partner (Celly \& Frazier, 1996; Coleman, 1990). Unilateral governance involves the use of external measurement, such as measuring a partner's performance or monitoring the actions of the partner (Heide, 1994).

The constant monitoring of a party over a partner provides the party with information for detecting opportunistic behaviors of the partner (Williamson, 1985). For instance, a buyer's monitoring of a supplier involves review of the supplier's performance or evaluation of the supplier's inventory levels and delivery performance. Thus, monitoring discourages suppliers from behaving opportunistically (Stump \& Heide, 1996), thereby protecting buyers from exploitation or unexpected low performance levels on the part of suppliers.

Parties in exchange relationships tend to feel uncertainty when they do not monitor the performance of their partners (Anderson, 1985). A lack of monitoring causes information deficiency, because exchange parties cannot assess the performance of transaction partners (Kim, Sung, and Jung, 2015; Rindfleisch \& Heide, 1997). In fact, exchange partners may behave opportunistically to take advantage of the information asymmetry.

Given that monitoring is the unilateral surveillance of a partner, one drawback is that monitoring may offend the partner's sense of autonomy (Ouchi, 1979). Monitoring signals a lack of confidence in an exchange partner. The constant monitoring of a partner might therefore provoke negative reactions from the partner (Ghoshal \& Moran, 1996). Although monitoring is an effective way to ensure that an exchange partner behaves in a certain way, it may create negative feelings for the party being watched (Green, 2000). Thus, monitoring may result in negative outcomes due to the lack of cooperation between buyer and supplier (Williamson, 1985). The exchange partner could defect to an alternative partner, for example, thus leading to termination of the relationship.

Because benevolent buyers will always signal suppliers regarding their concern for the well-being of partners, the negative effects of monitoring will be lessened by this benevolence. On the other hand, if a buyer is not benevolent toward a supplier, then the negative effects of monitoring will worsen the relationship. The monitoring of suppliers establishes standards for quality, delivery, incentives, and other positive outcomes, as well as potentially enhancing a buyer's ability to detect and restrain a supplier from opportunism in the first place (Leenders \& Fearon, 1993). Thus, our first hypothesis is:

H1: When a supplier trusts the benevolence of a buyer, the monitoring of a buyer over the supplier will enhance the performance of the supplier.

Bilateral governance is based on the collective rather than the individual goals of two parties involved in an exchange relationship (Gundlach \& Achrol, 1993). Bilateral governance relies on relational norms (Hur, Nam and Carvalho, 2014; Gundlach \& Achrol, 1993; Weitz \& Jap, 1995; Lusch \& Brown, 1996), which stimulate efforts for mutual benefits between the buyer and the supplier (Kim \& Cho, 2014; Weitz \& Jap, 1995).

Exchange parties relying on bilateral governance show high levels of flexibility in the relationship (Noordewier, John, and Nevin, 1990). The norm of flexibility is defined as the expectation that each party is willing to adapt to changing circumstances without resorting to renegotiation (Young, Sapienza and Baumer, 2003). The norm of flexibility implies that exchange parties are willing to modify the terms of exchange if a particular practice proves detrimental to either party (Heide \& John, 1992). The norm of flexibility therefore contributes to the interfirm relationship by guiding the relationship in uncertain environments (Gundlach \& Achrol, 1993).

Relational norms, however, negatively influence the success of new products (Lee, Ha, and Kim, 2014; Ayers, Dahlstrom, and Skinner, 1997). The tendency to be flexible to the demands of colleagues by following the norm of flexibility may prevent people from expressing contingencies at odds with the opinions of presumed experts. Although these relational norms yield high levels of satisfaction, professional disagreements and disputes that are essential to product success may not be presented in the interest of maintaining flexibility (Ayers et al., 1997). 
Exchange partners with too close of a relationship to one another often fail to produce optimum levels of performance (Nahapiet \& Ghoshal, 1998; Uzzi, 1996). This is mainly due to a lack of opportunity to access innovative information provided by non-close partners (Grabher, 1993). Relational norms tend to be vaguely defined, and thus they are broadly interpreted. Relational norms are vulnerable to manipulation by the more powerful party (Achrol \& Gundlach, 1999). Overly close relationships increase organizational inertia and limit the openness of a relationship to information, to the extent that parties face difficulty in changing behaviors or finding alternative ways of doing things (Uzzi, 1996; Leonard-Barton, 1995).

The norm of flexibility also has a weak spot, which is the norm does not specify optimal behaviors in dealing with unique situations. Thus there might be disparity regarding the levels of flexibility a party expects from its partner. Exchange parties might have misunderstandings in certain situations, and might expect different types of behavior from partners (Young, Sapienza and Baumer, 2003). Ambiguous expectations and misunderstandings can undermine cooperation between exchange parties, thereby deteriorating interfirm performance (Weitz \& Jap, 1995).

Ambiguous expectations and misunderstandings might be mitigated by the existence of buyer benevolence, insofar as suppliers believe that benevolent buyers tend to behave for the benefit of the supplier.

H2: When a supplier trusts the benevolence of a buyer, the reliance of bilateral governance will enhance the performance of the supplier.

\section{Plural Governance}

Plural governance refers to a buyer's use of multiple types of governance in a relationship with a supplier. Due to the positive and negative effects of unilateral and bilateral governance, exchange parties must use plural governance to produce higher levels of performance (Weitz \& Jap, 1995).

An exchange party who wants to use plural governance should meet an important condition for producing positive performance. Namely, the plural governances should complement each other. Otherwise, conflict might exist between governances, thereby leading to low performance levels by one or both parties in the exchange relationship. For instance, the negative effects of monitoring are potentially mitigated by the norm of flexibility. Because exchange parties that engage in the norm of flexibility pursue collective goals, the negative effects of monitoring are alleviated by this tacit cooperation. Thus, the norm of flexibility complements monitoring as an example of advantageous plural governance.

One question is whether a buyer that seeks to establish a norm of flexibility with its supplier needs to monitor the supplier. Because the norm of flexibility is not specific in terms of how to handle unique situations, exchange parties might not fully understand one another within all contexts (Weitz \& Jap, 1995). A party that has obtained information by way of monitoring a partner will always have a chance to resolve issues quickly, thereby improving performance.

The weakness of relational norms is that they are fragile and require continuous maintenance (Joshi \& Stump, 1999). In contrast, comprehensive monitoring practices enhance channel performance by establishing clear expectations, providing immediate feedback and guiding modification (Bello \& Gilliland, 1997). Monitoring therefore complements the norm of flexibility.

Complementation between monitoring and relational norms enables buyers with high trust in suppliers the likelihood of enhancing the performance of suppliers. There are two reasons for this. First, because the norm of flexibility stresses a mutually beneficial relationship (Gundlach \& Achrol, 1993), flexibility tends to establish an environment in which suppliers positively interpret any monitoring conducted by buyers. Buyer monitoring therefore signals suppliers about the importance of being monitored for the benefit of both parties (Sachdev, Bello, and Pilling, 1994). Accordingly, supplier perceptions of the significance of high performance and the achievement of mutual goals lead to enhanced levels of supplier performance. 
The critical question for exchange partners is how to facilitate conditions under which plural governance is optimally complementary. Because a perceived lack of buyer benevolence on the part of a supplier will interfere with any voluntary adjustment from the supplier (Ganesan, 1994), the buyer is vulnerable to unforeseen circumstances such as a need to order more parts or cancel the order. Additionally, the negative feelings generated by monitoring in a partnership characterized by low benevolence prohibit suppliers from actively responding to buyer requests (Ghoshal \& Moran, 1996). Accordingly, a party's belief in the benevolence of its partner is a condition that should exist for effective plural governance.

A party's trust in the benevolence of its partner is a unilateral belief in the partner's concern about the well-being of the trusting party. Thus, buyer benevolence represents an essential condition for a supplier to accept a buyer's methods of governance. Accordingly, the use of plural control mechanisms will lead to improved supplier performance in relationships in which suppliers trust the benevolence of buyers.

In contrast, in the absence of belief in a buyer's benevolence, a supplier might be suspicious about a buyer's methods of governance. A party with a low level of trust in its partner is less likely to find productive solutions to disagreements (Moorman, Zaltman, and Deshpande, 1992), and less likely to adopt a cooperative approach to problem solving (Schurr \& Ozanne, 1985). Therefore, a buyer using plural governance is less likely to enhance supplier performance when the supplier does not trust the buyer's benevolence. Thus the third hypothesis:

H3: When a supplier trusts the benevolence of a buyer, the buyer's use of plural governance (unilateral and bilateral) will enhance the performance of the supplier.

Figure 1. Hypothesized Model:

Benevolence, Interfirm Governance, and Performance

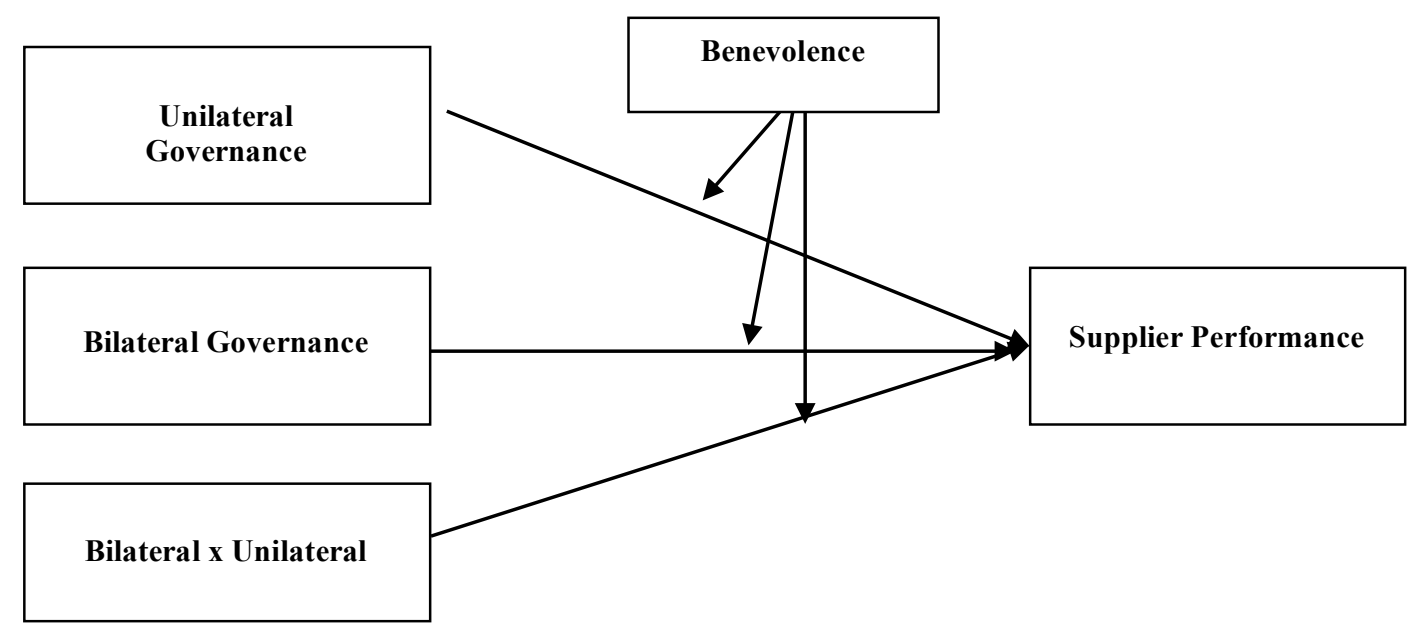

Note: The solid arrows are hypothesized to be significant relationships, whereas the dashed arrows are hypothesized to be non-significant relationships.

\section{METHODOLOGY}

\section{Research Setting and Data Collection}

This study considers the relationships between a buyer and its major supplier. We define the major supplier as the supplier accounting for the largest share of the manufacturer's purchase of parts in the past year. The major supplier's business partners are the firms with which the supplier has exchange relationships. For the methodology herein, the major supplier served as the referent for all the questions in the mail survey. We selected these relationships based on the theory that a manufacturer's major supplier represents the most intense types of interaction between partners, as well as the greatest opportunities to develop interfirm governance. 
For this study's sample, 850 manufacturers were selected randomly from a Dun and Bradstreet mailing list. We used standard industrial classification (SIC) codes 3011 to 3999, which is expected to have eliminated industry-specific influences on governance structure.

As this research is concerned with the governance structures and benevolence of buyers in particular, the heads of purchasing departments of manufacturing companies were chosen as key informants. Purchasing managers are responsible for purchasing materials from suppliers. Therefore, purchasing managers are experts who are knowledgeable about buyer relationships with suppliers (Hutt \& Speh, 1992).

We mailed the questionnaire to each informant and instructed him or her to complete it with respect to the firm's major supplier and its business partners. After callbacks and a second mailing, we collected a total of 195 responses (a $23 \%$ response rate).

\section{Non-Response Bias}

Corporate Affiliations Plus 2000 list was used for gathering secondary data on the characteristics of the companies for both responding and non-responding firms. We compared the demographic characteristics of these firms, including the location, firm size, number of employees, and total sales, but found no significant differences (e.g., $\mathrm{p}<$ .54 for the number of employees in both groups of firms). In addition, we measured the response rates and found no significant difference. These results demonstrate that the data was not skewed by a non-response bias.

\section{Measure Development}

We collected existing measures of the focal variables from previous research. Measure development was carried out in two stages. In the first stage, existing measures for our constructs were gathered from the literature. In the second stage, in-depth interviews were conducted with three purchasing managers. The purpose of these interviews was to check the relevance of the items developed in the first stage. Based on the input from the interviewed purchasing managers, the wording of some of the items was revised (see Table 2). All items used a 7-point Likert scale, with 1 indicating "strongly disagree," and 7 indicating "strongly agree."

We employed interfirm benevolence to measure a supplier's unilateral belief about buyer concern for its well-being. The scale addresses buyer concerns about supplier interests, business growth, and business success (Ryu, Hung, and Mana, 2014). Secondly, the items that were designed to measure unilateral governance were used in the assessment of the manufacturer's unilateral control over its supplier's level of inventory and its quality control procedures, as well as the performance review of the supplier (Noordewier et al., 1990). Thirdly, the items designed for bilateral governance were used to measure the extent to which each party would be willing to adapt to changing circumstances without resorting to renegotiation (Min, Kwak, and Lee, 2015).

We measured plural governance by multiplying the prevalence of bilateral governance with unilateral governance. Finally, supplier performance was measured according to buyer satisfaction with the supplier in terms of delivery time, the percentage of defective parts, the provision of information, and overall satisfaction (Noordewier, John and Nevin, 1990) (See Table 1). 
Table 1. Measurement Items and Validity Assessment

\begin{tabular}{|c|c|}
\hline Trust & Reliability $=.88$ \\
\hline 1. When making important decisions, the supplier is concerned about our welfare. & .81 \\
\hline 2. When it comes to things that are important to us, we can depend on the supplier's support. & .73 \\
\hline 3. We can count on the supplier to consider how its decisions and actions will affect us. & .77 \\
\hline 4. Our firm can count on the supplier to be sincere. & .83 \\
\hline Monitoring & Reliability $=.75$ \\
\hline Our firm monitors the inventory levels of our major supplier. & .75 \\
\hline $\begin{array}{l}\text { The production processes of our major supplier are to a large extent determined by our firm's } \\
\text { requirements. }\end{array}$ & .58 \\
\hline We regularly conduct performance reviews of our major supplier. & .77 \\
\hline $\begin{array}{l}\text { Any engineering changes by our major supplier are to a large extent determined by our firm's } \\
\text { requirements. }\end{array}$ & $*$ \\
\hline Bilateral Governance & Reliability $=.80$ \\
\hline $\begin{array}{l}\text { Both our firm and our major supplier expect that each company will be flexible regarding the other } \\
\text { company's request for changes. }\end{array}$ & .72 \\
\hline $\begin{array}{l}\text { Both our firm and our major supplier expect to be able to make any adjustments necessary to cope with } \\
\text { changing circumstances. }\end{array}$ & .83 \\
\hline $\begin{array}{l}\text { Both our firm and our major supplier expect to be flexible with each other if flexibility helps the other } \\
\text { company. }\end{array}$ & .62 \\
\hline Supplier Performance & Reliability $=.78$ \\
\hline Your firm is satisfied with the service quality of the major supplier. & .72 \\
\hline Your firm is satisfied with the overall performance of the major supplier. & .68 \\
\hline Your firm is satisfied with the on-time delivery performance of the major supplier. & .70 \\
\hline
\end{tabular}

Note: $\mathrm{SFL}=$ standardized factor loading

\section{Construct Validity}

We conducted a scale development procedure for each variable. First, exploratory factor analyses were run for each set of constructs. We assessed the validity of the constructs, including benevolence, unilateral governance, bilateral governance, and supplier performance. We conducted an item-total correlation test to exclude any ill-fitting items. We then subjected the remaining items to a confirmatory factor analysis (CFA) using LISREL. Subsequently, reliability analyses were run for each construct to determine whether all the measures showed satisfactory reliability.

After the scale purification process, a measurement model with acceptable fit indices was identified $\left(\chi^{2}=78.25\right.$, df $=$ $59, \mathrm{p}=.033 ; \mathrm{GFI}=.92 ; \mathrm{CFI}=.95 ; \mathrm{IFI}=.95 ; \mathrm{RMSEA}=.057)$. The multiple correlation of each item was between .41 and .58, which indicates convergent validity (Bollen, 1989). All the factor loadings were highly significant (p < .01), which shows convergent validity and unidimensionality of the measures (Gerbing \& Anderson, 1988). Subsequently, reliability tests were conducted for each construct to determine whether all the measures demonstrated satisfactory coefficient reliability. The reliability of all the constructs was above .70 (Peter, 1979). Thus, these measures demonstrate adequate convergent validity and reliability.

We evaluated the discriminant validity of all four of the latent variables through $\chi^{2}$ difference tests. We tested all constructs in pairs (a total of six tests) to determine whether the results of the restricted model (whose correlations were fixed as one) were significantly worse than the results of the freely estimated model (whose correlations were freely estimated). All $\chi^{2}$ differences were highly significant, indicating sufficient discriminant validity (Anderson $\&$ Gerbing, 1988). For example, the $\chi^{2}$ difference between unilateral and bilateral governance was $\chi^{2}(1)=24.25(\mathrm{p}<$ .01 ), indicating that these two constructs were sufficiently distinct from one another. The results of CFA, including the goodness-of-fit index, factor loadings, and reliability, are reported in Table 1.

Because the value for plural governance was calculated as an interaction between unilateral and bilateral governance, the existence of multicollinearity between the interaction variables was possible (Jaccard \& Wan, 1995). To eliminate potential problems associated with multicollinearity, we mean-centered the variables of monitoring and the norm of information sharing (Aiken \& West, 1991). The mean-centered variables were multiplied to establish the plural control mechanisms. The mean-centered variables of monitoring and the norm of 
flexibility were also used for hypotheses testing.

Table 2. Descriptive Statistics and Correlations Matrix

\begin{tabular}{lrrrr}
\hline & $\mathbf{1}$ & $\mathbf{2}$ & $\mathbf{3}$ & $\mathbf{4}$ \\
\hline 1. Trust & 1.00 & & & \\
2. Bilateral Governance & .11 & 1.00 & & \\
3. Unilateral Governance & -.10 & -.23 & 1.00 & \\
4. Performance & .18 & .04 & -.06 & 1.00 \\
\hline Mean & 5.16 & 4.48 & 3.53 & 4.98 \\
Standard Deviation & 1.17 & 1.05 & 1.00 & 1.25 \\
\hline
\end{tabular}

Note: sample size $=172$

\section{ANALYSIS AND RESULTS}

\section{Hypotheses Testing}

We employed structural models to test the hypotheses. The factors of the four constructs were used to test the hypotheses. We used bilateral governance and unilateral governance as an exogenous variable, benevolence as a moderating variable, and supplier performance as an endogenous variable.

The findings are presented in Table 3. Hierarchical moderated regression was conducted to test the interaction effects of bilateral governance and benevolence (BILABENE: BILA $\times$ BENE) and (UNIBENE: UNILA $\times$ BENE) on supplier performance (PERFORM). To analyze the significance of the interaction effects, model 1, excluding the cross-product variable of BILABENE, was compared with model 2, using BILABENE and UNIBENE to determine whether the incremental R2 was significant (Anderson, 1985).

To analyze the significance of the three-way interaction effects, model 2, including the cross-product variables of BILABENE and UNIBENE, was compared with the three- way interaction effects of bilateral governance, unilateral governance, and benevolence on supplier performance (BIUNIBENE: BILA $\times$ UNILA $\times$ BENE). Model 2 was compared with model 3, using BI UNI BENE to determine whether the incremental R2 was significant.

$$
\begin{aligned}
\text { PERFORM } & =\mathrm{b} 0+\mathrm{b} 1 \text { BILA }+\mathrm{b} 2 \mathrm{UNILA}+\mathrm{b} 3 \text { BENE }+\mathrm{b} 4 \text { BILABENE } \\
& +\mathrm{b} 5 \text { UNIBENE }+\mathrm{b} 5 \text { BIUNIBENE }
\end{aligned}
$$

Table 3 shows that the R2 values for model 2 and for model 1 were .132 and .110 , respectively, and that both were significant at $<.05$. The increment in R2 was .22, significant at $<.05$. This provides evidence that the significant amount of variance in supplier performance is explained by the existence of buyer benevolence.

The result indicates that the interaction variable of unilateral governance and benevolence is significantly related to supplier performance $(\beta=.175, \mathrm{p}<.05)$, which supports hypothesis 1 . The result also shows that the interaction variable of bilateral governance and benevolence is significantly related to supplier performance $(\beta=.185, \mathrm{p}<.05)$, which supports hypothesis 2 . The variance inflation factor (VIF) values were well below the cutoff value of 10 , suggesting that multicollinearity is not present (Aiken and West, 1991). The three-way interaction variable of bilateral governance and unilateral governance and benevolence is also significantly related to supplier performance $(\beta=.177, \mathrm{p}<.05)$, which supports hypothesis 3 .

The effects of the control variable, relationship length, are not significantly related to supplier performance. Relationship length has a positive impact on supplier performance (see Table 3), but it is not significant. It appears that the length of the relationship between a buyer and its supplier is not important in increasing interfirm performance. 
Table 3. Hierarchical Moderated Regression Analysis for Supplier Performance

\begin{tabular}{l|cc}
\hline \multicolumn{1}{c}{ Independent Variables } & \multicolumn{1}{c}{ Dependent Variables (MONIT) } \\
\cline { 2 - 3 } Main Effects & & VIF \\
\hline Unilateral & $-.122(-1.17)$ & 1.732 \\
Bilateral & $.099(-0.84)$ & 1.524 \\
Trust & $.315(2.89)^{* *}$ & 1.756 \\
Length & $.041(0.38)$ & 1.185 \\
Adj. ${ }^{2}$ & .110 & 1.362 \\
\hline Interaction Effects & & 1.117 \\
\hline Bilateral x Bene & $.185(2.40)^{*}$ & \\
Unilateral x Bene & $.175(2.28)^{*}$ & \\
Cumulative Adj. $\mathrm{R}^{2}$ & .132 & $.022^{*}$ \\
$\mathrm{R}^{2}$ Increment & & $.177(2.37)^{*}$ \\
\hline Interaction Effects & .152 & $.020^{*}$ \\
\hline Bilateral x Unilateral x Bene &
\end{tabular}

Note: t-tests are two-tailed for hypothesized effects

$* * \mathrm{p}<.01 * \mathrm{p}<.05$

VIF: collinearity statistic

\section{DISCUSSION}

This study shows that interfirm benevolence on the part of a buyer may increase interfirm performance in cases where the buyer uses unilateral and bilateral governance structures individually, as well as uses both governance structures simultaneously. Because both governance structures have weak spots, interfirm benevolence plays an important role in compensating for the weaknesses of the governance types and increasing interfirm performance.

When a supplier feels the benevolence of its buyer, unilateral governance by the buyer positively affects the performance of the supplier. Some research shows a negative relationship between unilateral governance of a buyer and supplier performance (Uzzi, 1996; Nahapiet \& Ghoshal, 1998; Grabher, 1993; Ouchi, 1979). When a buyer unilaterally controls a supplier, such as managing the supplier's inventory levels, the supplier's autonomy is dishonored. The bad feelings engendered by this type of control may cause the supplier to resist the buyer's governing attempts (Ouchi, 1979). The supplier may show a further lack of interest in meeting buyer expectations, which leads to poor supplier performance.

Bilateral governance by a buyer also positively influences supplier performance when the supplier trusts the benevolence of the buyer. Previous research reports that an exchange party with a bilateral-based governance relationship often fails to produce optimum levels of performance due to a lack of access to innovative technology and information (Uzzi, 1996; Nahapiet \& Ghoshal, 1998; Grabher, 1993). The results of that study indicate that a buyer using bilateral governance must earn the belief of the supplier by way of buyer benevolence. Otherwise, the buyer may have difficultly increasing the performance of the supplier.

Unilateral and bilateral governance structures show a complementary relationship when a supplier trusts the benevolence of the buyer. Individual governance has its own weak spots, so a buyer who needs to control a supplier may want to use multiple complementary governance structures. Our findings indicate that when a benevolent buyer uses both unilateral and bilateral governance structures simultaneously, suppliers perform positively.

\section{Managerial Implications}

This study guides firms toward producing better supplier performance. The essential implication of this study for practitioners is that exchange parties should develop benevolent relationships with exchange partners. When a party gives a partner reason to believe in its benevolent intentions, then the parties develop a better relationship, leading to superior performance. The results of this study imply that without a benevolent relationship, interfirm performance is not necessarily guaranteed. Firms should not take optimal performance levels for granted without developing benevolent relationships and governance mechanisms. 
Another implication of this study is that a benevolent buyer should determine appropriate interfirm governance, accordingly. A buyer needs various governance structures to protect against a partner's lack of interest in its welfare. This study implies that a buyer can rely on both unilateral governance and bilateral governance when a supplier believes in the buyer's benevolence.

The study indicates that a benevolent buyer's reliance on multiple governance structures results in enhanced supplier performance. When a supplier trusts in the benevolence of its buyer, the complementary relationship between unilateral governance and bilateral governance plays an important role in increasing the quality of the supplier's performance. Because reliance on unilateral governance potentially triggers negative reactions from suppliers, a buyer needs to develop and use bilateral governance. Therefore, benevolent buyers should simultaneously use both governance structures to enhance supplier performance.

\section{Limitations and Future Research}

This study adopts monitoring as an example of unilateral governance, while other mechanisms of unilateral governance, such as vertical control, are alternative examples of unilateral governance. A buyer is able to control a supplier by compelling the supplier to accept the buyer's requests, for example. This is a much more active form of unilateral governance than monitoring. Accordingly, the effects of buyer benevolence on a vertical control-based relationship and supplier performance might be different.

The norm of flexibility is used to represent bilateral governance in this study. The norm of information sharing or the norm of conflict resolution are alternative aspects of bilateral governance. Because the norm of flexibility is just one of several governance mechanisms, the results about the effects of buyer benevolence on supplier performance may differ according to other governance mechanisms. Thus, future studies might try using other mechanisms of bilateral governance to obtain more robust results.

In future studies, we may investigate the simultaneous use of multiple governance structures and their impact on firm performance in the context of other trust dimensions, such as honesty or credibility. Because honesty and credibility have been analyzed as critical dimensions of trust in previous literature, we focus only on interfirm benevolence. Further studies may include and utilize other trust dimensions in different combinations to evaluate their impact on interfirm performance.

\section{REFERENCES}

Achrol, R. S., \& Gundlach, G. T. (1999). Legal and social safeguards against opportunism in exchange. Journal of Retailing, 75(1), 107-124.

Anderson, E. (1985). The salesperson as outside agent or employee: a transaction cost analysis. Marketing science, 4(3), $234-254$.

Anderson, J. C., \& Gerbing, D. W. (1988). Structural equation modeling in practice: A review and recommended two-step approach. Psychological bulletin, 103(3), 411.

Atuahene-Gima, K., \& Li, H. (2002). When does trust matter? Antecedents and contingent effects of supervisee trust on performance in selling new products in China and the United States. Journal of Marketing, 66(3), 61-81.

Ayers, D., Dahlstrom, R., \& Skinner, S. J. (1997). An exploratory investigation of organizational antecedents to new product success. Journal of Marketing Research, 107-116.

Bello, D. C., \& Gilliland, D. I. (1997). The effect of output controls, process controls, and flexibility on export channel performance. the Journal of Marketing, 22-38.

Bollen, K. A. (1989). Structural equations with latent variables. John Wiley \& Sons.

Bradach, J. L., \& Eccles, R. G. (1989). Price, authority, and trust: From ideal types to plural forms. Annual review of sociology, 97-118.

Cannon, J. P., Achrol, R. S., \& Gundlach, G. T. (2000). Contracts, norms, and plural form governance. Journal of the Academy of Marketing Science, 28(2), 180-194.

Celly, K. S., \& Frazier, G. L. (1996). Outcome-based and behavior-based coordination efforts in channel relationships. Journal of marketing research, 200-210.

Coleman James, S. (1990). Foundations of social theory. Cambridge MA (Belnkamp).

Das, T. K., \& Teng, B. S. (1998). Between trust and control: Developing confidence in partner cooperation in alliances. Academy of management review, 23(3), 491-512.

Doney, P. M., \& Cannon, J. P. (1997). An examination of the nature of trust in buyer-seller relationships. the Journal of 
Marketing, 35-51.

Ganesan, S. (1994). Determinants of long-term orientation in buyer-seller relationships. the Journal of Marketing, 1-19.

Gerbing, D. W., \& Anderson, J. C. (1988). An updated paradigm for scale development incorporating unidimensionality and its assessment. Journal of marketing research, 186-192.

Ghoshal, S., \& Moran, P. (1996). Bad for practice: A critique of the transaction cost theory. Academy of management Review, 21(1), 13-47.

Grabher, G. (1993). The embedded firm (pp. 255-277). London: Routledge.

Granovetter, M. (1982). The strength of weak ties: A network theory revisited. Social Structure and Network Analysis, 105-130.

Green, J. (2000). Tight squeeze at Chrysler. Business Week, 9, 54.

Gundlach, G. T., \& Achrol, R. S. (1993). Governance in exchange: contract law and its alternatives. Journal of Public Policy \& Marketing, 141-155.

Heide, J. B. (1994). Interorganizational governance in marketing channels. The Journal of Marketing, 71-85.

Heide, J. B., \& John, G. (1988). The role of dependence balancing in safeguarding transaction-specific assets in conventional channels. The Journal of Marketing, 20-35.

Heide, J. B., \& John, G. (1992). Do norms matter in marketing relationships?. The Journal of Marketing, 32-44.

Hur, Y., Moriuchi, E., Ackerman, D., \& Rhee, J. H. (2014). Inter-Organizational Power and Control Mechanisms: The Role of Benevolence and Credibility. Journal of Marketing Thought, 1 (2), 49-57.

Hur, Y., Nam, S., \& Carvalho, S. W. (2014). The Mediating Effect of Trust and Value on Loyalty. Journal of Marketing Thought, 1 (3), 48-58.

Hutt, M. D., \& Speh, T. W. (1989). Business marketing management: a strategic view of industrial and organizational markets.

Jaccard, J., \& Wan, C. K. (1995). A paradigm for studying the accuracy of self-reports of risk behavior relevant to AIDS: Empirical perspectives on stability, recall bias, and transitory influences. Journal of Applied Social Psychology, 25(20), 1831-1858.

Jaccard, J., \& Wan, C. K. (1995). Measurement error in the analysis of interaction effects between continuous predictors using multiple regression: Multiple indicator and structural equation approaches. Psychological bulletin, 117(2), 348.

Jap, S. D., \& Ganesan, S. (2000). Control mechanisms and the relationship life cycle: Implications for safeguarding specific investments and developing commitment. Journal of marketing research, 37(2), 227-245.

Joshi, A. W., \& Stump, R. L. (1999). Transaction cost analysis: Integration of recent refinements and an empirical test. Journal of Business-to-Business Marketing, 5(4), 37-71.

Jun, S. K., Kabadayib, S., \& Ryu, S. M. (2014). Evolution of Trust in Exchange Relationship. Journal of Marketing Thought, 1 (3), 11-22.

Kim, K. H., \& Cho, Yoon C. (2014). The Moderating Effects of a Network Norm of Obligation. Journal of Marketing Thought, 1(2), 1-9.

Kim, K. H., Sung, Min, \& Jung, G. O. (2015). Revisiting TSI: How TSI Contributtes to the Buyer-Seller Relationship. Journal of Marketing Thought, 1(4), 10-21.

Lal, R. (1990). Improving channel coordination through franchising. Marketing Science, 9(4), 299-318.

Lee, K. W., Ha, J. \& Kim, H. R. (2014). Complementary Effects of Marketing Network and Structure holes on Supplier's Perceived New Product Development Performance of Buyer: Moderating Effect of Technological Uncertainty. Journal of Marketing Thought, 1 (1), 50-58.

Leenders, M. R., Fearon, H. E., \& England, W. B. (1993). Purchasing and materials management, Homewood, IL: Richard D. Irwin.

Leona S. Aiken, Stephen G. West, \& Raymond R. Reno. (1991). Multiple regression: Testing and interpreting interactions. Sage.

Leonard-Barton, D. (1995). Wellspring of knowledge. Harvard Business School Press, Boston, MA.

Lim, Y. H., Smith, S. \& Kim, E. J. (2014). The Relationship between Environmental Uncertainty and Opportunism in Marketing Channels: the Moderating Effect of Network Embeddedness. Journal of Marketing Thought, 1(1), 22-42.

Lusch, R. F., \& Brown, J. R. (1996). Interdependency, contracting, and relational behavior in marketing channels. The Journal of Marketing, 19-38.

Madhavan, R., \& Grover, R. (1998). From embedded knowledge to embodied knowledge: new product development as knowledge management. The Journal of marketing, 1-12.

Min, J. H., Kwak, K. S., \& Lee, J. I. (2015). Environmental Uncertainty and Interfirm Controls: The moderating Effect of Honesty. Journal of Marketing Thought, 1(4), 22-28.

Moorman, C., Zaltman, G., \& Deshpande, R. (1992). Relationships between providers and users of market research: The dynamics of trust. Journal of marketing research, 29(3), 314-328.

Nahapiet, J., \& Ghoshal, S. (1998). Social capital, intellectual capital, and the organizational advantage. Academy of management review, 23(2), 242-266.

Noordewier, T. G., John, G., \& Nevin, J. R. (1990). Performance outcomes of purchasing arrangements in industrial buyervendor relationships. the journal of marketing, 80-93.

Ouchi, W. G. (1979). A Conceptual Framework for the Design of Organizational Control Mechanisms. Management Science, 25(9), 833-848.

Peter, J. P. (1979). Reliability: A review of psychometric basics and recent marketing practices. Journal of marketing research, 
6-17.

Rindfleisch, A., \& Heide, J. B. (1997). Transaction cost analysis: Past, present, and future applications. the Journal of Marketing, 30-54.

Ryu, S. M., Ken, H., \& Jafar M. (2014). Control mechanisms for Protecting the Benevolent Partner in the Relatinship between Marketing Channel Members. Journal of Marketing Thought, 1(1), 43-49.

Sachdev, H. J., Bello, D. C., \& Pilling, B. K. (1995). Control mechanisms within export channels of distribution. Journal of Global Marketing, 8(2), 31-50.

Schurr, P. H., \& Ozanne, J. L. (1985). Influences on exchange processes: Buyers' preconceptions of a seller's trustworthiness and bargaining toughness. Journal of consumer research, 939-953.

Stump, R. L., \& Heide, J. B. (1996). Controlling supplier opportunism in industrial relationships. Journal of Marketing Research, 431-441.

Uzzi, B. (1996). The sources and consequences of embeddedness for the economic performance of organizations: The network effect. American sociological review, 674-698.

Weitz, B. A., \& Jap, S. D. (1995). Relationship marketing and distribution channels. Journal of the academy of Marketing Science, 23(4), 305-320.

Williamson, O. E. (1985). The economic institutions of capitalism: Firms. Markets, Relational Contracting, New York, 26ff.

Wilson, D. T. (1995). An integrated model of buyer-seller relationships. Journal of the academy of marketing science, 23(4), 335-345.

Young, G., Sapienza, H., \& Baumer, D. (2003). The influence of flexibility in buyer-seller relationships on the productivity of knowledge. Journal of Business Research, 56(6), 443-451. 